\title{
sciendo

\section{Analysis of Operation Parameters of Fish Refrigeration by Exergy Analysis. Case Study}

\author{
Edvins TEREHOVICS ${ }^{1 *}$, Ivars VEIDENBERGS ${ }^{2}$, Dagnija BLUMBERGA ${ }^{3}$ \\ ${ }^{1-3}$ Institute of Energy Systems and Environment, Riga Technical University, \\ Azenes iela 12/1, Riga, LV-1048, Latvia
}

\begin{abstract}
Unlike energy efficiency, in terms of exergy efficiency it is possible to compare the existing operation of an energy conversion system with the ideal operation. Exergy loses and exergy destruction make it possible to identify the shortcomings of an existing system, which should be improved immediately. With exergy analysis, it is possible to identify the priority actions that need to be taken in order to improve the functioning of the system: greater exergy loss prevention is the highest priority. Energy efficiency refers to the useful work and investments needed to obtain useful work and investments needed to obtain energy efficiency; this is important to some extent, but the effectiveness of exergy makes it possible to compare system performance with the ideal. Results shows that the highest exergy destruction of a single-stage compressor refrigeration system from all working condition is found when ambient temperature and freezer temperature difference is $10^{\circ} \mathrm{C}$, pressure in compressor is $0.62 \mathrm{MPa}$, ammonia temperature after compressor is $90{ }^{\circ} \mathrm{C}$, total exergy destruction of single-stage compressor refrigeration system $97.84 \mathrm{~kW}$. The highest exergy efficiency of a single-stage compressor refrigeration system from all the working conditions is found when ambient temperature and freezer temperature difference is $39^{\circ} \mathrm{C}$, pressure in compressor is 0.45 MPa, ammonia temperature after compressor is $128^{\circ} \mathrm{C}$, exergy efficiency of a single-stage compressor refrigeration system is $59.76 \%$. The highest total exergy destruction of a two-stage compressor refrigeration system from among all the working conditions is found to be when the ambient temperature and freezer temperature difference is at $13{ }^{\circ} \mathrm{C}$, pressure in compressor $0.44 \mathrm{MPa}$, ammonia temperature after compressor $76{ }^{\circ} \mathrm{C}$, total exergy destruction $83.86 \mathrm{~kW}$. The highest exergy efficiency of a two-stage compressor refrigeration system from among all the working conditions is found to be at an ambient temperature and freezer temperature difference of $39^{\circ} \mathrm{C}$, pressure in compressor $0.56 \mathrm{MPa}$, ammonia temperature after compressor $92{ }^{\circ} \mathrm{C}$, exergy efficiency $53.55 \%$.
\end{abstract}

Keywords - Compressor; condenser; efficiency; energy; food industry; Sankey diagram

\section{INTRODUCTION}

Energy consumption in industry has become an important aspect of competitive action. Energy efficiency is one of the key aspects of reducing emissions from industry. Increasing energy consumption and high emissions indicate that current refrigeration equipment is ineffective. Therefore, in order to reduce the environmental impact of these problems, solutions should be sought to reduce energy consumption and improve the efficiency of refrigeration systems, resulting in reduced environmental impacts [1]-[4].

In any energy conversion system, with the help of energy balance, the input and output flows of all types of energy are indicated. The incoming energy flow can be one or more, but

\footnotetext{
* Corresponding author.

E-mail address: e.terehovics@inbox.lv
} 
the outgoing energy flow can only be as a product or energy loss. In its turn, an exergy analysis based on the second law of thermodynamics examines the quality of the input and output energy of the system. The energy analysis does not give a real idea about the energy system's functioning in relation to the ideal. In addition, the energy analysis does not provide information about factors causing losses in the elements of the energy conversion system. In order to overcome these limitations, an exergy analysis should be used; it allows to find shortcomings in the power supply system, which could not be identified by energy analysis. Exergy analysis examines the reduction in available energy quality and identifies the causes of energy losses and their location in energy conversion system. Exergy analysis makes it possible to determine the amount of energy that can be used for useful work [5].

With the exergy efficiency, unlike energy efficiency, it is possible to compare the existing operation of energy conversion system with the ideal operation. Exergy loses and exergy destruction make it possible to identify shortcomings in the existing system, which should be improved immediately. With an exergy analysis, it is possible to identify the priority actions that need to be taken in order to improve the functioning of the system: greater exergy loss prevention is of the highest priority. Energy efficiency refers to the useful work and investments needed to obtain useful work and investments needed to obtain energy efficiency; this is important to some extent, but the effectiveness of exergy makes it possible to compare system performance with the ideal. Therefore, this indicator shows the maximum potential for improving the performance of the system. Energy losses must be reduced because they reduce energy efficiency, but exergy destruction can be more important than exergy losses; exergy losses are linked with energy losses, but exergy destruction (linked with irreversible processes) is not examined in the scope of energy analysis [6].

Exergy analysis is an effective method for objective evaluation of energy conversion processes in refrigeration systems. In comparison with the energy balance, exergy analysis is used to define the types and causes of energy losses based on the quality of energy lost during heat and cooling processes [7], [8].

Exergy analysis includes exergy balance and efficiency in order to evaluate and improve energy conversion systems. The purpose of exergy analysis is to identify significant causes and actual values of exergy efficiency and losses. Improving the exergy efficiency will allow to reduce the amount of irreversible processes in the system and the loss of exergy. This will improve the performance of the system, thereby generating electricity savings that ultimately reduce operating costs [9], [10].

Refrigeration systems are important in different sectors, for example, food industry, because they are used for a variety of applications, such as water cooling, air conditioning and refrigeration; therefore, it is important that refrigeration systems work as efficiently as possible to avoid wasteful energy consumption [11]-[13].

A number of scientific and engineering techniques are available for analysing energy use in industrial processes that are constantly being developed in order to find possible energy-saving solutions that can identify the extent and priorities for energy loss reduction.

The study [13] is devoted to the use of exergy in the design and analysis of industrial processes; the analysis of exergy and energy analysis is compared in the study. The results showed that exergy analysis during industrial process design often shows those losses that are already known. However, exergy analysis also identifies the efficiency of the process; this aspect, together with the identified energy losses, determines the potential for improvement of the design process.

In the study [14], a glass furnace was analysed using energy and exergy analysis. The results showed that the methodology applied depends on the process of the energy system being 
studied. Using exergy analysis, it was possible to identify exergy loss and destruction, as well as to identify processes that need to be improved. The identified processes were the same as those indexed by energy analysis. One of the most important findings during the study was the high rate of unavoidable exergy destruction in many processes, such as incineration, leading to low exergy efficiency.

The study [15] highlights exergy analysis of the drying process. Dinser and Sahin [16] proposed a new analysis model for drying processes based on exergy analysis. The study [17] used an exergy analysis to analyse the evaporator for fruit juice processing. The study [18] analysed the modelling of evaporator performance and the actual operation of the dairy plant. In turn, Zhang et al. [19] compared a five-effect evaporator with a three-effect evaporator with mechanical steam recompression in milk processing. One group of researchers - Choi et al. [20] carried out exergy analysis of vapor recompression evaporator, indicating new design solutions and optimum operating parameters. The results of the particular study showed that the exergy destruction that occurs in a particular component depends on its specificity and how it is affected by other system components. Exergy analysis does not always show the real losses that can be reduced, while in the case of advanced exergy analysis, these losses can be identified [21]. The advanced exergy analysis method described in literature sources is used during the research of many industrial processes, such as refrigeration equipment [21] and cogeneration plants [22] and research [23] about the manufacturing of rubber products. The results of these studies showed the benefits of a progressive exergy analysis, because priorities for reducing energy loss are ranked on the basis of exergy destruction. Published studies have shown that the use of various exergy methods for the analysis of industrial process components can detect loss reduction options and allow to compare different alternatives. The author of the study [24] points out that the analysis of exergy in industry is not used because this method of analysis is considered to be complex and the results obtained are difficult to interpret and use. The author of the study also proposes to prepare an overview of methods of analysis of industrial processes and to provide an explanation of the results of each method and their application. Such a review of thermodynamic analysis of possible applications and interpretation of results would provide better understanding of practical application of industrial process analysis methods in comparison with conventional engineering techniques.

\section{Methodology}

\subsection{Overview of the Analysed Fish Processing Company}

The factory uses six freezers: two freezers are used for freezing fish at $-32{ }^{\circ} \mathrm{C}$ : two freezers are used to store frozen fish at $-18{ }^{\circ} \mathrm{C}$ to $-20^{\circ} \mathrm{C}$; Two freezers are used to store semi-finished products at a temperature of $\sim 0^{\circ} \mathrm{C}$. The factory purchases fresh fish from local fishermen, however, makes up the difference of total supply needed for production through purchase of frozen fish from another supplier. Fresh fish are initially frozen at $-32{ }^{\circ} \mathrm{C}$, then transferred to a freezer where frozen fish is stored. The frozen fish, in turn, are placed in the freezer immediately.

All freezers are operated by 5 two-stage compressors and 3 single-stage compressors. Usually one two-stage or/and one single-stage compressor works. Single-stage compressors are used to provide the required temperatures in freezers where frozen fish and finished products are stored. Two-stage compressors, however, are used to maintain the freezer temperatures in which fresh fish are frozen. 
Ammonia is used as a refrigerant in compressors, but local river water is used for cooling condensers and compressors.

The compressor performance is recorded in the journal. The following data is recorded every 2 hours:

- Ammonia temperature before and after two-stage compressor stages and flash chamber pressure;

- Ammonia temperature before and after one-step compressor;

- Water temperature before and after compressor and condenser as well as ammonia condensation pressure;

- Freezer temperature;

- Outdoor temperature;

- Temperature of the ammonia vapor fed to the freezer evaporators.

Within the framework of this study, exergy efficiency as well as exergy destruction of the refrigeration system for freezing fish and parameters affecting exergy efficiency were analysed.

\subsection{Outline of the Methodology}

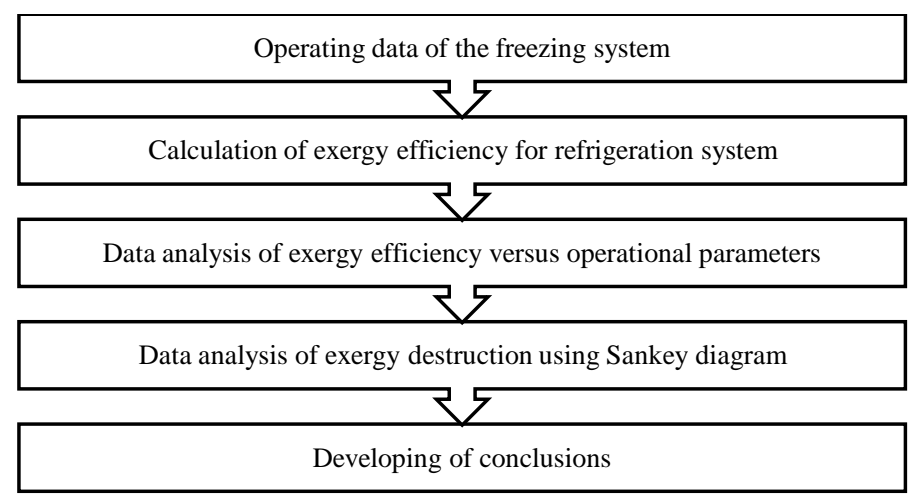

Fig. 1. Algorithm of exergy efficiency analysis for refrigeration system.

The algorithm consists of 5 blocks (Fig. 1). In the first block, data of the technical and operational parameters of the refrigeration system are collected. In the second block, calculation of exergy efficiency for the single-stage and two-stage compressor refrigeration systems are made. In the third block, data analysis of the refrigeration system exergy efficiency versus operational parameters such as pressure in condenser and ammonia vapor temperature after compressor performed. In the fourth block data analysis of exergy destruction in the single-stage and two-stage refrigeration systems using Sankey diagram are performed. Writing conclusions of results took place in the last block.

For refrigeration system exergy efficiency and exergy destruction calculation we use the following formulas.

Exergy destruction in compressor [25], [26]: 


$$
E x_{\text {dest.comp }}=T_{0} \cdot m \cdot\left(s_{2}-s_{1}\right) \text {, }
$$

where

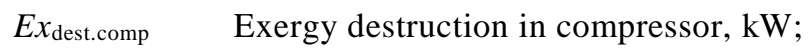

$T_{0}$

Ambient air temperature, $\mathrm{K}$;

$m$

Mass flow rate of amonia vapor in compressor, $\mathrm{kg} / \mathrm{s}$;

$s_{2}$

Entropy of ammonia vapor after compressor, $\mathrm{kJ} /(\mathrm{kg} \cdot \mathrm{K})$;

$s_{1}$

Entropy of ammonia vapor before compressor, $\mathrm{kJ} /(\mathrm{kg} \cdot \mathrm{K})$.

Exergy destruction in condenser [23], [24]:

$$
E x_{\text {dest.cond }}=T_{0} \cdot\left[m \cdot\left(s_{4}-s_{2}\right)+\frac{m \cdot\left(h_{2}-h_{4}\right)}{T_{0}}\right] \text {, }
$$

where

$E x_{\text {dest.cond }} \quad$ Exergy destruction in condenser, $\mathrm{kW}$;

$m$

Mass flow rate of ammonia vapor in condenser, $\mathrm{kg} / \mathrm{s}$;

$s_{2}$

Entropy of ammonia vapor before condenser, $\mathrm{kJ} /(\mathrm{kg} \cdot \mathrm{K})$;

$s_{4}$

Entropy of ammonia vapor after condenser, $\mathrm{kJ} /(\mathrm{kg} \cdot \mathrm{K})$;

$h_{2} \quad$ Enthalpy of ammonia vapor before condenser, $\mathrm{kJ} / \mathrm{kg}$;

$h_{4} \quad$ Enthalpy of ammonia vapor after condenser, $\mathrm{kJ} / \mathrm{kg}$.

Exergy destruction in expansion valve [25], [26]:

$$
E x_{\text {dest.expan }}=T_{0} \cdot m \cdot\left(s_{5}-s_{4}\right)
$$

where

$E x_{\text {dest.expan }} \quad$ Exergy destruction in expansion valve, $\mathrm{kW}$;

$m \quad$ Mass flow rate of ammonia vapor in expansion valve, $\mathrm{kg} / \mathrm{s}$;

$s_{4} \quad$ Entropy of ammonia vapor before expansion valve, $\mathrm{kJ} /(\mathrm{kg} \cdot \mathrm{K})$;

$s_{5} \quad$ Entropy of ammonia vapor after expansion valve, $\mathrm{kJ} /(\mathrm{kg} \cdot \mathrm{K})$.

Exergy destruction in evaporator [25], [26]:

$$
E x_{\text {dest.evap }}=T_{0} \cdot\left[m \cdot\left(s_{1}-s_{5}\right)+\frac{m \cdot\left(h_{1}-h_{5}\right)}{T_{\mathrm{L}}}\right] \text {, }
$$

where

$E x_{\text {dest.evap }} \quad$ Exergy destruction in evaporator, $\mathrm{kW}$;

$m$

Mass flow rate of ammonia vapor in evaporator, $\mathrm{kg} / \mathrm{s}$;

$s_{1}$

Entropy of ammonia vapor before evaporator, $\mathrm{kJ} /(\mathrm{kg} \cdot \mathrm{K})$;

$S_{5}$

Entropy of ammonia vapor after evaporator, $\mathrm{kJ} /(\mathrm{kg} \cdot \mathrm{K})$;

$h_{1}$

Enthalpy of ammonia vapor after evaporator, $\mathrm{kJ} / \mathrm{kg}$; 
$h_{5} \quad$ Enthalpy of ammonia vapor before evaporator, $\mathrm{kJ} / \mathrm{kg}$;

$T_{\mathrm{L}} \quad$ Temperature in freezer, $\mathrm{K}$.

Exergy of refrigeration load [25], [26]:

$$
{ }^{E x} Q_{\mathrm{L}}=-m \cdot\left(h_{1}-h_{5}\right) \cdot\left(1-\frac{T_{0}}{T_{\mathrm{L}}}\right),
$$

where

$E x_{Q \mathrm{~L}}$

Exergy of refrigeration load, kW;

$m$

Mass flow rate of ammonia vapor in evaporator, $\mathrm{kg} / \mathrm{s}$.

Refrigeration system exergy efficiency [25], [26]:

$$
\eta_{\mathrm{ex}}=1-\left(\frac{E x_{\text {dest.comp }}+E x_{\text {dest.cond }}+E x_{\text {dest.expan }}+E x_{\text {dest.evap }}}{W}\right)=\frac{E x_{Q_{\mathrm{L}}}}{W},
$$

where

$\eta_{\mathrm{ex}} \quad$ Exergy efficiency of refrigeration system;

W Compressor power input, $\mathrm{kW}$.

\section{Results}

Calculation of exergy efficiency and exergy destruction on the basis of data received from fish processing company about single-stage and two-stage refrigeration system season $2017 / 2018$.

\subsection{Exergy Efficiency and Exergy Destruction in Single-Stage Refrigeration System}

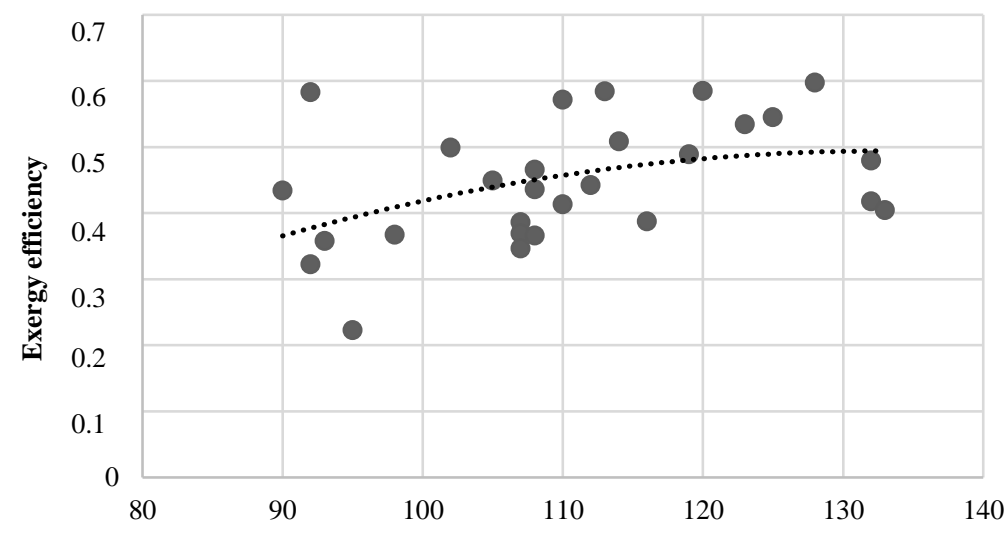

Ammonia vapor temperature after compressor, ${ }^{\circ} \mathrm{C}$

Fig. 2. Single-stage compressor refrigeration system exergy efficiency depending on ammonia vapor temperature after compressor. 
Fig. 2 shows information on changes in the exergy efficiency of a single-stage compressor refrigeration system depending on the ammonia vapor temperature after the compressor. From the information presented, it can be concluded that the exergy efficiency increases with the increase of ammonia vapor temperature after the compressor. The increase in ammonia vapor temperature after the compressor is explained by the amount of ammonia vapor sucked into the compressor, which is higher in the warmer months of the year than in the coldest months. The second reason for the ammonia temperature after the compressor increases is the increase in the temperature of the cooled water, which ensures the cooling of the compressor. Exergy efficiency reaches a maximum of 0.6 at ammonia vapor temperature of $128^{\circ} \mathrm{C}$. With ammonia temperatures above $128{ }^{\circ} \mathrm{C}$, the efficiency of exergy decreases.

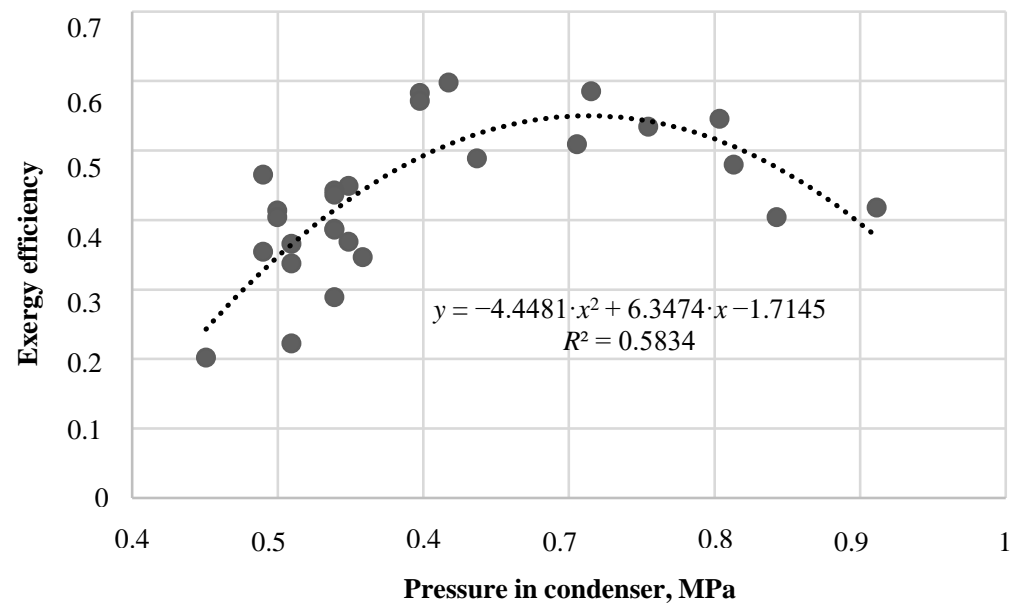

Fig. 3. Single-stage compressor refrigeration system exergy efficiency depending on pressure in condenser.

Fig. 3 shows information on changes in the exergy efficiency of a single stage compressor refrigeration system depending on the pressure in the condenser. From the information shown, it can be concluded that the exergy efficiency increases with increasing the pressure in the condenser to $0.72 \mathrm{MPa}$, but decreases above the condenser pressure of $0.72 \mathrm{MPa}$. The increase in pressure in the condenser can be explained by the increase in the water temperature of the condenser cooling. In contrast, the reduction in exergy efficiency when the condenser pressure exceeds $0.72 \mathrm{MPa}$ is explained by the high temperature of the condenser cooling and the reduction of the ambient temperature. This situation is typical of the autumn months when the ambient temperature is lower than the water temperature used to cool the condenser. Exergy efficiency reaches a maximum value of 0.60 at a pressure of $0.62 \mathrm{MPa}$ in a condenser. 


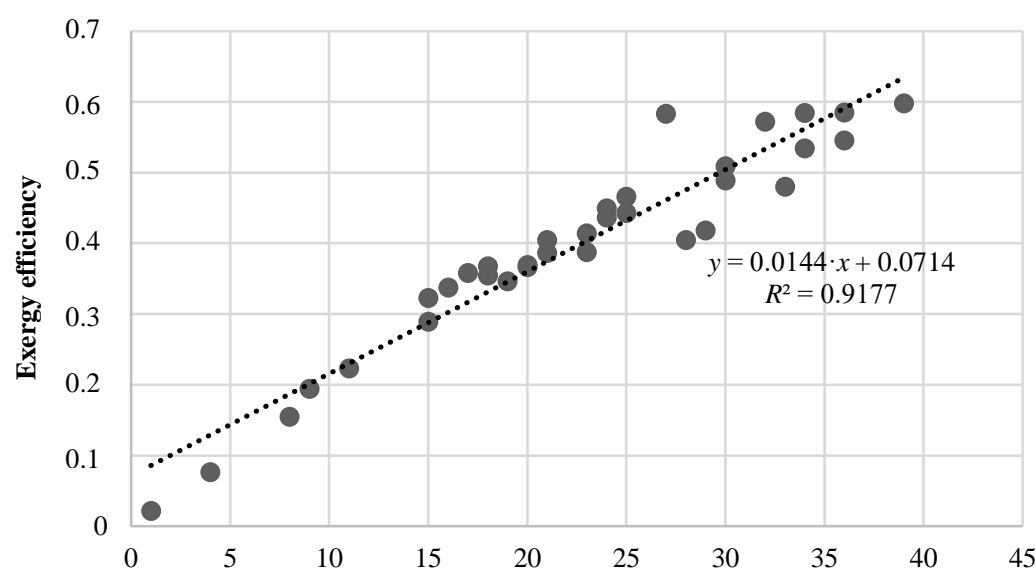

Ambient temperature and evaporator temperature difference, ${ }^{\circ} \mathrm{C}$

Fig. 4. Single-stage compressor refrigeration system exergy efficiency depending on ambient temperature and refrigerator temperature difference.

Fig. 4 shows information on changes in the exergy efficiency of a single-stage compressor refrigeration system depending on the differences between ambient and freezer temperature. From the information presented, it can be concluded that the exergy efficiency increases with an increasing temperature difference between the environment and freezer temperature. The increase in the ambient temperature and freezer temperature difference can be explained by the increase in ambient temperatures as the freezer temperature is constant. Taking into account the formulas for calculating the exergy efficiency of the refrigeration system and refrigeration load exergy described in the previous chapter, it can be concluded that the exergy efficiency and refrigeration load exergy is influenced by the difference between the ambient and the freezer temperature as evidenced by the correlation coefficient indicated in the graph. Exergy efficiency reaches a maximum value of 0.60 at a temperature difference of $39^{\circ} \mathrm{C}$ and a minimum exergy value of 0.02 at a temperature difference of $1{ }^{\circ} \mathrm{C}$.

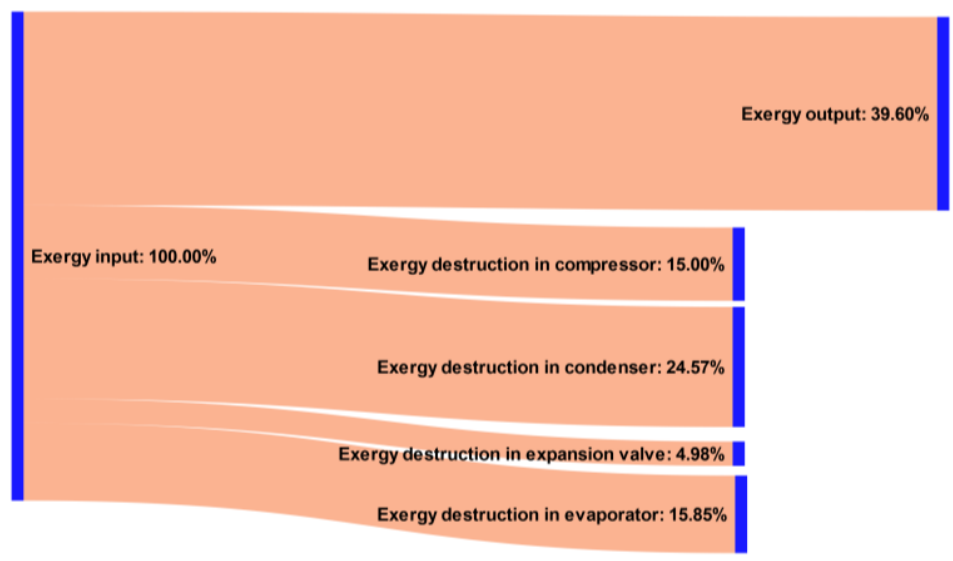

Fig. 5. Exergy destruction in single-stage compressor refrigeration system. 
Fig. 5 shows information about the average amount of exergy and exergy destruction in the single-stage refrigeration system. The biggest exergy destruction takes place in a condenser followed by a $15.85 \%$ in the evaporator and a $15.00 \%$ in the compressor, while the smallest exergy destruction with $4.98 \%$ takes place in the expansion valves. The amount of exergy in the refrigeration system is $39.60 \%$.

The amount of exergy destruction in system elements depends on the ambient temperature and entropy change during processes in the system elements. Taking into account that the ambient temperature cannot be changed, but entropy can, it is necessary to choose the equipment or process providing modes that reduce the entropy increase.

\subsection{Exergy Efficiency and Exergy Destruction in Two-Stage Refrigeration System}

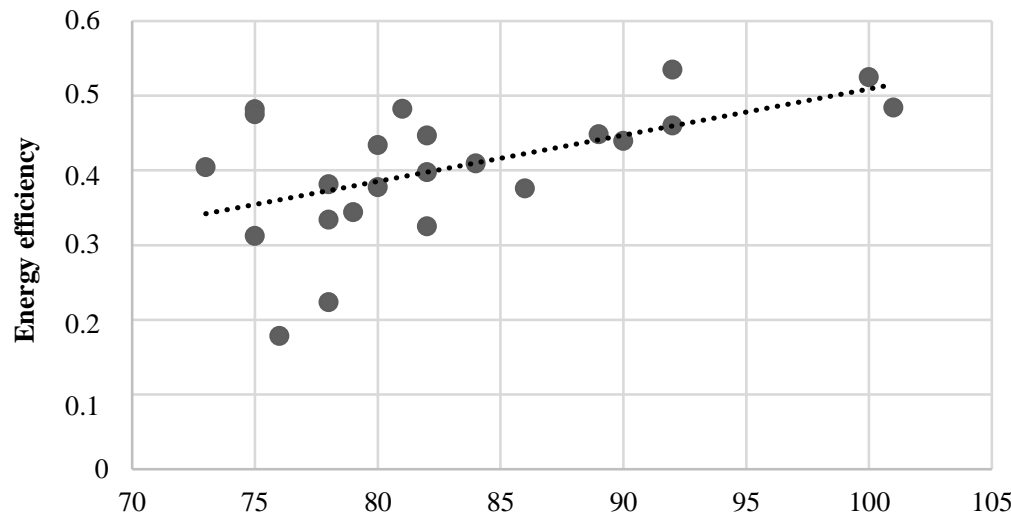

Ammonia vapor temperature after compressor, ${ }^{\circ} \mathrm{C}$

Fig. 6. Two-stage compressor refrigeration system exergy efficiency depending on ammonia vapor temperature after compressor.

Fig. 6 shows information on changes in the exergy efficiency of two-stage compressor refrigeration system depending on the ammonia vapor temperature of the compressor. From the information presented, it can be concluded that the exergy efficiency increases with the increase of ammonia vapor temperature after the compressor. The increase in ammonia vapor temperature after compressor can be explained by the amount of ammonia vapor sucked into the compressor, which is higher in the warmer months of the year than in the coldest months. The second reason for the ammonia temperature after the compressor increases is the increase in the temperature of the cooled water, which ensures cooling of the compressor. Exergy efficiency reaches a maximum value of 0.54 at an ammonia vapor temperature of $92{ }^{\circ} \mathrm{C}$. 


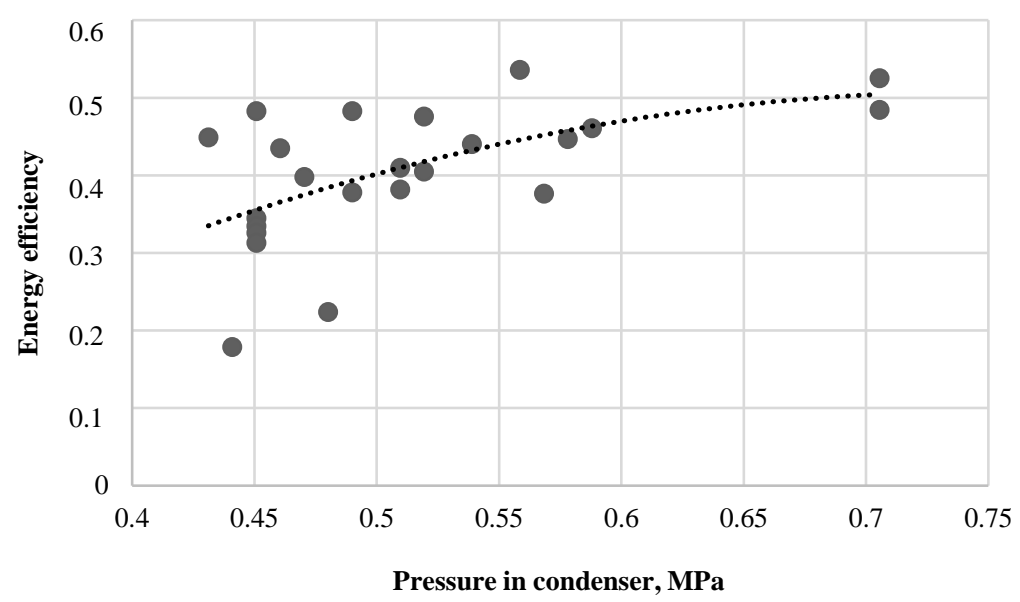

Fig. 7. Two-stage compressor refrigeration system exergy efficiency depending on ambient temperature and evaporator temperature difference.

Fig. 7 shows information on two-stage changes in the compressor refrigeration system's exergy efficiency depending on the pressure in the condenser. From the information presented, it can be concluded that the exergy efficiency increases with increasing pressure in the condenser. Exergy efficiency reaches a maximum value of 0.54 at a pressure of $0.56 \mathrm{MPa}$ in the condenser. The increase in pressure in the condenser can be explained by the increase in the water temperature of the condenser cooling. The condenser cooling water temperature reaches its maximum value in the warmer months of the year. Conversely, the low correlation between the efficiency of the exergy of the refrigeration system and the pressure in the condenser can be explained by the fact that other parameters, such as the ambient temperature, also affect the efficiency of exergy.

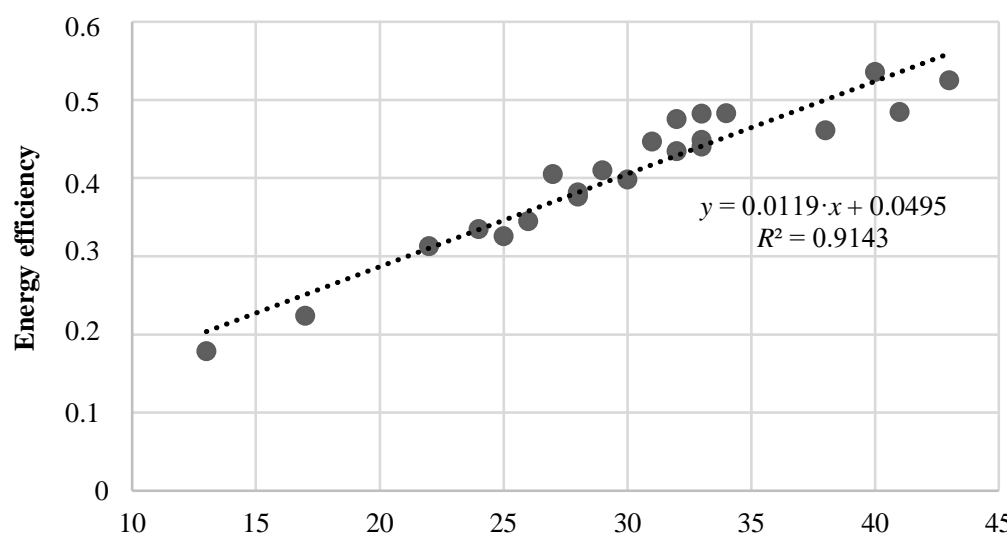

Ambient temperature and evaporator temperature difference, ${ }^{\circ} \mathrm{C}$

Fig. 8. Two-stage compressor refrigeration system exergy efficiency depending on ambient temperature and refrigerator temperature difference. 
Fig. 8 shows information on changes in the exergy efficiency of the two-stage compressor refrigeration system depending on the difference between ambient and freezer temperatures. From the information presented, it can be concluded that the exergy efficiency increases with increasing temperature difference between the environment and freezer temperatures. The increase in the ambient temperature and freezer temperature difference can be explained by the increase in ambient temperatures as the freezer temperature is constant. Taking into account the formulas for calculating the exergy efficiency of the refrigeration system and refrigeration load exergy described in the previous chapter, it can be concluded that the exergy efficiency and refrigeration load exergy is influenced by the difference between the ambient and the freezer temperatures as evidenced by the correlation coefficient indicated in the graph. Exergy efficiency reaches a maximum value of 0.54 at a temperature difference of $40{ }^{\circ} \mathrm{C}$ and a minimum exergy value of 0.18 at a temperature difference of $13{ }^{\circ} \mathrm{C}$.

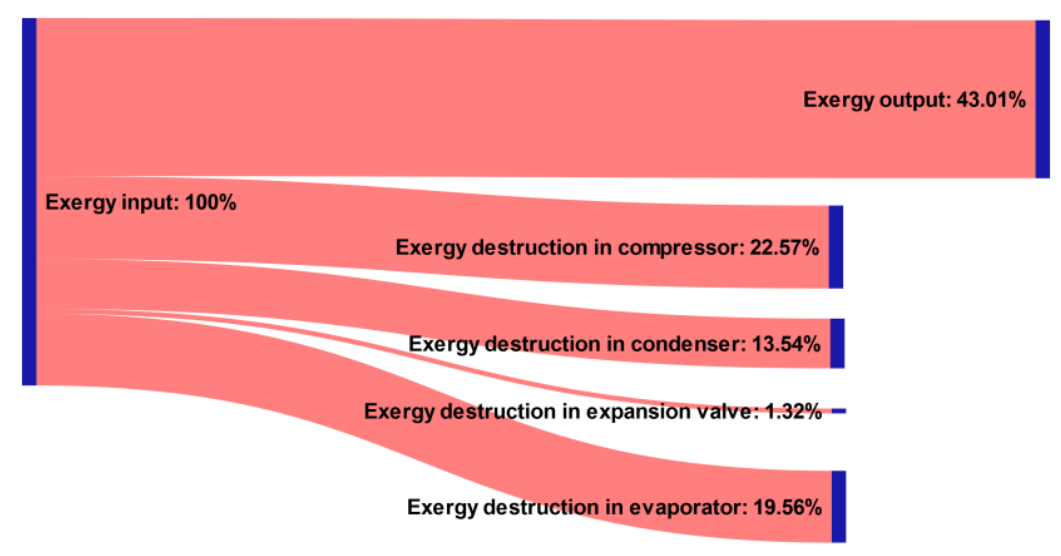

Fig. 9. Exergy destruction in two-stage compressor refrigeration system.

Fig. 9 shows information about the average amount of exergy and exergy destruction in the two-stage refrigeration system. The biggest exergy destruction takes place in the compressor followed by a $19.56 \%$ in the evaporator and a $13.54 \%$ in the condenser, while the smallest exergy destruction with $1.32 \%$ takes place in the expansion valves. The amount of exergy in the refrigeration system is $43.01 \%$.

The amount of exergy destruction in system elements depends on the ambient temperature and entropy change during processes in the system's elements, that the ambient temperature cannot be changed, but entropy can be changed, then it is necessary to choose the equipment or process providing modes that reduce the entropy increase.

\section{Conclusions}

In this study, exergy analysis of single-stage and two-stage compressor refrigeration system were carried out. The exergy efficiency and total exergy destruction of the system in the different operating conditions were investigated.

The highest total exergy destruction of the single-stage compressor refrigeration system among all the working conditions is found to be ambient temperature and freezer temperature difference of $1{ }^{\circ} \mathrm{C}$, pressure in compressor $0.62 \mathrm{MPa}$, ammonia temperature after compressor $90{ }^{\circ} \mathrm{C}$, total exergy destruction $97.84 \mathrm{~kW}$. The highest exergy efficiency of a single-stage 
compressor refrigeration system among all the working conditions is found to be ambient temperature and freezer temperature difference $39^{\circ} \mathrm{C}$, pressure in compressor $0.45 \mathrm{MPa}$, ammonia temperature after compressor $128{ }^{\circ} \mathrm{C}$, exergy efficiency $59.76 \%$.

The highest total exergy destruction of the two-stage compressor refrigeration system among all the working conditions is found to be ambient temperature and freezer temperature difference of $13{ }^{\circ} \mathrm{C}$, pressure in compressor $0.44 \mathrm{MPa}$, ammonia temperature after compressor $76^{\circ} \mathrm{C}$, total exergy destruction $83.86 \mathrm{~kW}$. The highest exergy efficiency of two-stage compressor refrigeration system for among all the working conditions is found to be ambient temperature and freezer temperature difference $39^{\circ} \mathrm{C}$, pressure in compressor $0.56 \mathrm{MPa}$, ammonia temperature after compressor $92^{\circ} \mathrm{C}$, exergy efficiency $53.55 \%$.

The exergy destruction in the refrigeration system elements is linked with the pressure and temperature changes caused by the processes taking place in each element of the system, as well as the temperature difference between the environment and the temperature of the elements of the refrigeration system.

\section{ACKNOWLEDGEMENT}

This research is funded by European Maritime and Fisheries Fund, project "Improving production efficiency in the fish processing companies".

\section{REFERENCES}

[1] Khan Md. N., et al. Energy and Exergy Analysis of Vapour Compression Refrigeration System with R12, R22, R134a. International Journal of Emerging Technology and Advanced Engineering 2015:5:210-216.

[2] Bai T., et al. Advanced exergy analyses of an ejector expansion transcritical $\mathrm{CO}_{2}$ refrigeration system. Energy Conversion and Management 2016:126:850-861. doi:10.1016/j.enconman.2016.08.057

[3] Lallouche A., Kolodyaznaya V., Boulkrane M., Baranenko D. Low Temperature Refrigeration as an Alternative AntiPest Treatment of Dates. Environmental and Climate Technologies 2017:20(1):24-35. doi:10.1515/rtuect-2017-0008

[4] Bajcinovci B., Jerliu F. Achieving Energy Efficiency in Accordance with Bioclimatic Architecture Principles. Environmental and Climate Technologies 2016:18(1):54-63. doi:10.1515/rtuect-2016-0013

[5] Arshad A., et al. Energy and exergy analysis of fuel cells: A review. Thermal Science and Engineering Progress 2019:9:308-321. doi:10.1016/j.tsep.2018.12.008

[6] Costa V. A. F., et al. Mass, energy and exergy analysis of a biomass boiler: A portuguese representative case of the pulp and paper industry. Applied Thermal Engineering 2019:152:350-361. doi:10.1016/j.applthermaleng.2019.01.033

[7] Terehovics E., et al. Exergy analysis for district heating network. Energy Procedia 2017:113:189-193. doi:10.1016/j.egypro.2017.04.053

[8] Morosuk T., Tsatsaronis G. Advanced exergy-based methods used to understand and improve energy-conversion systems. Energy 2019:169:238-246. doi:10.1016/j.energy.2018.11.123

[9] Malwe P. D., et al. Exergy Analysis of Vapour Compression Refrigeration System. International Journal of Thermal Technologies 2014:4:54-57.

[10] Pons M., et al. Energy analysis of two-phase secondary refrigeration in steady-state operation, part 2: Exergy analysis and effects of phase change kinetics. Energy 2018:161:1291-1299. doi:10.1016/j.energy.2018.07.044

[11] Valencia G., et al. Comparative Evaluation of Different Refrigerants on a Vapor Compression Refrigeration System via Exergetic Performance Coefficient Criterion. Contemporary Engineering Sciences 2017:10:691-702. doi:10.12988/ces.2017.7763

[12] Belman-Flores J. M., et al. Exergy assessment of a refrigeration plant using computational intelligence based on hybrid learning methods. International Journal of Refrigeration 2018:88:35-44. doi:10.1016/j.ijrefrig.2018.01.004

[13] van Gool W. Exergy analysis of industrial processes. Energy 1992:17(8):791-803. doi:10.1016/0360-5442(92)90123-H

[14] McKenna R. C. Industrial energy efficiency: interdisciplinary perspectives on the thermodynamic, technical and economic constraints. Phd thesis. Bath: University of Bath, 2009.

[15] Aghbashlo M., Mobli H., Rafiee S., Madadlou A. A review on exergy analysis of drying processes and systems. Renewable and Sustainable Energy Reviews 2013:22:1-22. doi:10.1016/j.rser.2013.01.015

[16] Dincer I., Sahin A. Z. A new model for thermodynamic analysis of a drying process. International Journal of Heat and Mass Transfer 2004:47(4):645-652. doi:10.1016/j.ijheatmasstransfer.2003.08.013 
[17] Balkan F., Colak N., Hepbasli A. Performance evaluation of a triple-effect evaporator with forward feed using exergy analysis. International Journal of Energy Research 2005:29(5):455-470. doi:10.1002/er.1074

[18] Winchester J. Model based analysis of the operation and control of falling film evaporators. Palmerston North: Massey University, 2000.

[19] Zhang Y., Munir M. T., Udugama I., Yu W., Young B. R. Modelling of a milk powder falling film evaporator for predicting process trends and comparison of energy consumption. Journal of Food Engineering 2018:225:26-33. doi:10.1016/j.jfoodeng.2018.01.016

[20] Choi H. S., Lee T. J., Kim Y. G., Song S. L. Performance improvement of multiple-effect distiller with thermal vapor compression system by exergy analysis. Desalination 2005:182(1-3):239-249. doi:10.1016/j.desal.2005.03.018

[21] Morosuk T., Tsatsaronis G., Schult M. Conventional and advanced exergetic analyses: theory and application. Arabian Journal for Science and Engineering 2013:38(2):395-404. doi:10.1007/s13369-012-0441-9

[22] Petrakopoulou F., Tsatsaronis G., Morosuk T., Carassai A. Conventional andadvanced exergetic analyses applied to a combined cycle power plant. Energy 2012:41(1):146-152. doi:10.1016/j.energy.2011.05.028

[23] Vučkovič G. D., Stojiljkovič M. M., Vukič M. V., Stefanovič G. M., Dedeič E. M. Advanced exergy analysis and exergoeconomic performance evaluation of thermal processes in an existing industrial plant. Energy Conversion and Management 2014:85:655-662. doi:10.1016/j.enconman.2014.03.049

[24] Rosen M. A. Does industry embrace exergy? Exergy, An International Journal 2002:2(4):221-223. doi:10.1016/S1164-0235(02)00087-0

[25] Dincer I., Kanoglu M. Refrigeration Systems and Applications. $2^{\text {nd }}$ Edition. John Wiley \& Sons, 2010. doi:10.1002/9780470661093

[26] Alda D., Ciarlo D. Refrigeration Systems, Design Technologies and Developments. Nova Science Publishers, 2013. 